\title{
MONITORING THE PARAMETERS OF THE ROBOT-OPERATED QUALITY CONTROL PROCESS
}

\author{
Andrzej Burghardt' ${ }^{1}$, Krzysztof Kurc ${ }^{1}$, Dariusz Szybicki ${ }^{1}$, \\ Magdalena Muszyńska', Tomasz Szczęch²
}

1 The Faculty of Mechanical Engineering and Aeronautics, Department of Applied Mechanics and Robotics, Rzeszow University of Technology, 8 Powstancow Warszawy St., 35-959 Rzeszów, Poland, e-mail: tomasz. szczech@wskrz.com

2 Pratt\&Whitney Reszow S.A., Hetmanska 120,35-078 Rzeszów, Poland, e-mail: andrzejb@prz.edu.pl, kkurc@ prz.edu.pl,dszybick@prz.edu.pl, magdaw@prz.edu.pl

Received: 2016.12 .15

Accepted: 2017.02.01

Published: 2017.03.01

\begin{abstract}
The robotic test stations of the considered design, operated at industrial plants, must first perform the processes and tasks they have been intended for as required by manufacturing cost reduction. It is important that these processes are completed at minimum power consumption. The paper presents the process of system parameter selection for minimised power consumption with the example of an actual robotic test stand built for manufacturing quality control of stators. The developed solutions were tested on a real-life object and deployed on the measurement test stand.
\end{abstract}

Keywords: robot-operated station, guide vanes, working parameters, minimising energy consumption.

\section{INTRODUCTION}

Production of aircraft engine parts and components has a long timeline in the supplier portfolio of orders. On the one hand, long lead time orders on specific numbers of parts facilitate long-term production planning and assure a certain financial stability of the supplier; on the other hand, the orders prevent product development or increasing the number of manufactured components to boost profits. The only viable option for boosting profits on production is to perform the manufacturing process at the lowest possible human labour intensity and power consumption. This stimulates optimisation efforts which are directly translated into the economic results of the business $[6,7,8]$.

The paper presents the process of system parameter selection for minimised power consumption with the example of an actual robotic test stand built for manufacturing quality control of stators
$[1,2,4]$. The power consumption minimisation efforts included recording of process parameters and the search for modifications of TCP velocities and acceleration values to minimise power consumption without changing the processing time. To sum up, the paper presents a task for minimising the power consumption of the robotic test stand with its processing time unchanged.

The robotic test stand this paper pertains to is the property of the Research and Development Laboratory for Aerospace Materials. The test stand overview photograph is shown in Figure 1. The research efforts contemplated herein have a prospective use in the implementation of a similar test unit at Pratt \& Whitney Rzeszów Sp. z o.o.

\section{PROPOSED SOLUTION CONCEPT}

The process parameters that permit total power consumption by the robotic test stand system were selected with an electric power relationship. 


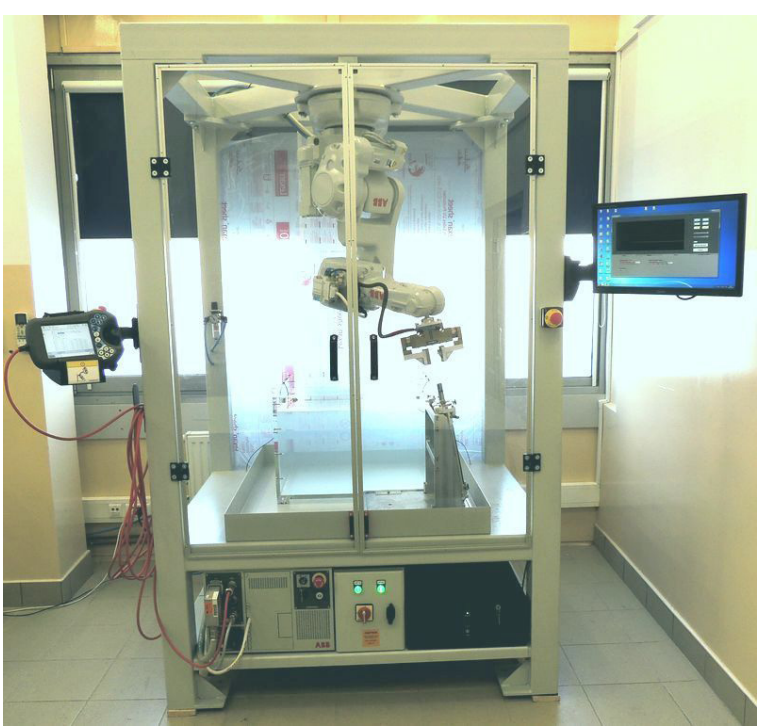

Fig. 1. Robotic test stand for the inspection of stator vane thickness

Electric power is the power of equipment multiplied by the operating time of equipment. The power is the product of the voltage and current drawn by the investigated system.

The robotic test stand features actuators that are PM (Permanent Magnetic) motors, so given a constant supply voltage of the test station, power consumption can be read from the current draw. The phenomenon of torque generation in electric motors is caused by the effect of the Lorenz force that depends on the current amps that flow through the motor winding and which are within the magnetic field of neodymium magnets, as installed in the robotic test stand. The torque generated by the robot actuators is related to the definition of the dynamics of the object and depends on the acceleration, velocity and motion resistance values.

To recapitulate, the changes in velocity and acceleration of the robot TCP affect the driving torque in the robot joints and the drive unit current draw, which translates into the power consumption level. The proposed solution assumes an adjustment of the TCP motion parameters so that the changes of velocity and acceleration at unchanged motion times minimise the power consumption.

The figure below shows the concept of the proposed solution. The robot TCP motion path is from point $P_{1}$ to $P_{2}$ (Fig. 2). Fig. $3 a$ and $3 b$ show the corresponding motion parameters.

Figure 3 shows the motion parameters (velocity Fig. 3a and acceleration Fig. 3c, the system power consumption Fig. 3e, and the total power Fig. 3g. The power consumption of the system

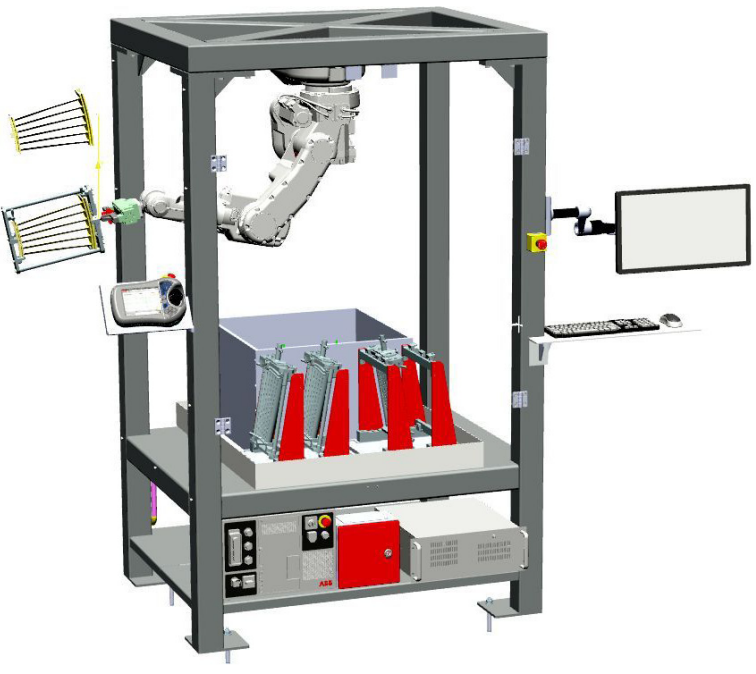

Fig. 2. Motion trajectory of the robot

can be reduced by changing the TCP motion parameters, i.e. increasing the velocity while reducing the acceleration (Fig. 3b, 3d, 3f, 3h). Note that the time of travel from $\mathrm{P}_{1}$ to $\mathrm{P}_{2}$ remains constant. It is contemplated herein that the robotic test stand work cycle time is not extended.

To recapitulate, the sought motion, velocity and acceleration parameters for the contemplated robot TCP must minimise the system power consumption without changing the robotic test stand work cycle time. This shall be done by minimising acceleration and increasing the velocity of motion.

\section{TEST RESULTS FOR THE ROBOTIC TEST STAND}

The robot TCP motion parameters were changed in RobotStudio. The RAPID programming language for the robots produced by $\mathrm{ABB}$ allows changing the motion velocity values, for instance by adding a velocity value to forward linear motion:

- MOVEL $\mathrm{P}_{1}$ z10 V100 tool

This instruction means that the robot will move from its current position to $\mathrm{P}_{1}$ at a velocity of $100[\mathrm{~mm} / \mathrm{s}]$. The velocity value is saved in a speed data variable. Aside from the TCP velocity value in $[\mathrm{mm} / \mathrm{s}]$, the speed data variable also includes the robot axis reorienting velocity expressed as $[\% / \mathrm{s}]$ and the external axis velocity values, if defined. An alternative way of defining velocity is to change it by a percentage value and adding a limit, for instance by applying the following instruction: 

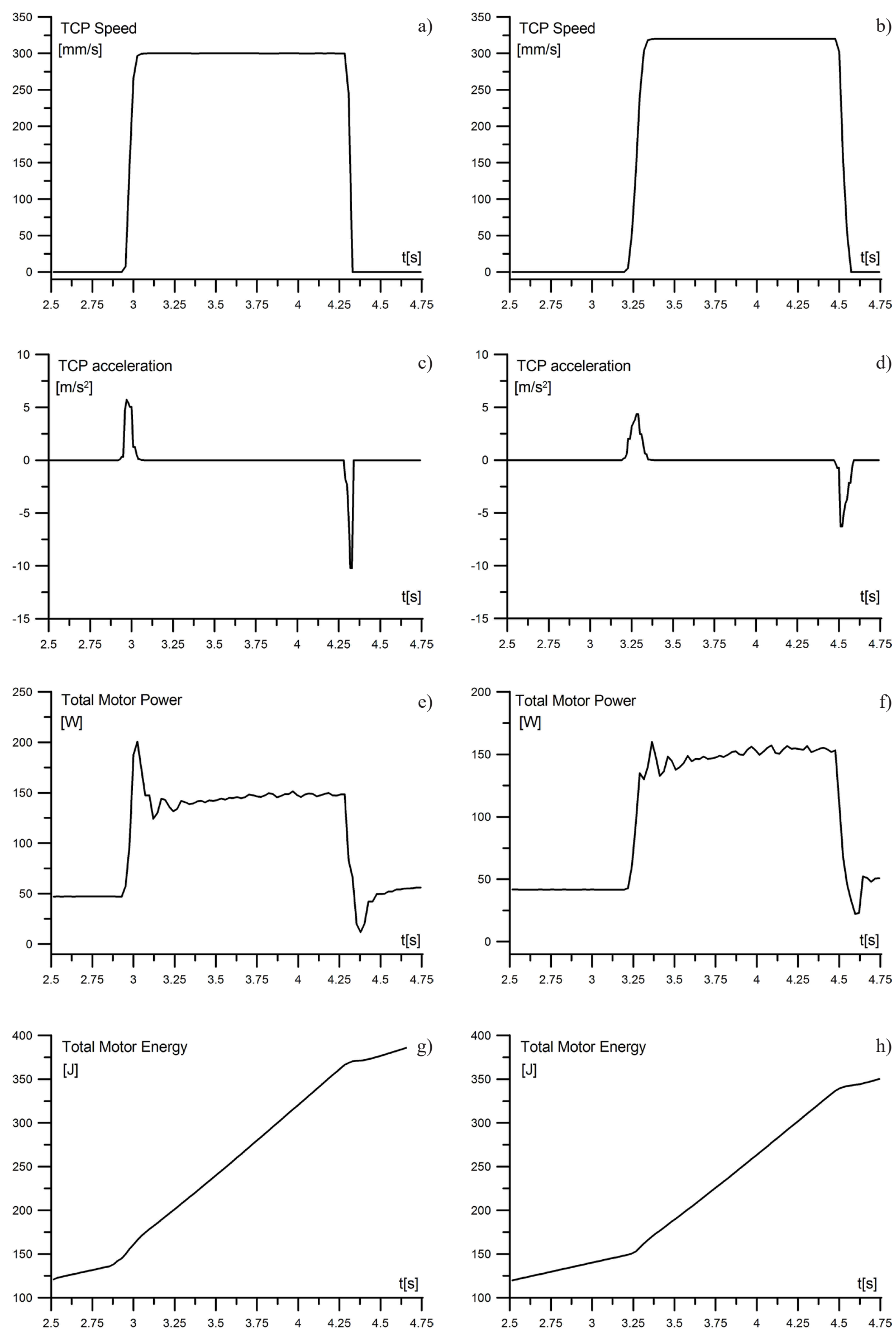

Fig. 3. TCP motion parameters and robotic test station work parameters 


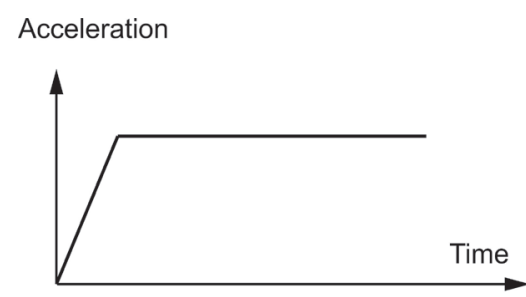

AccSet 100100 i.e. normal
Acceleration

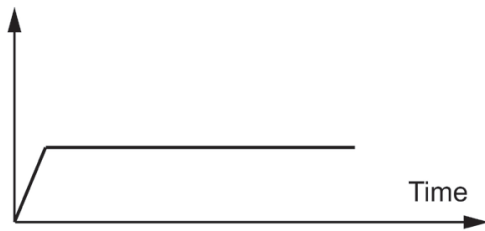

AccSet 30100
Acceleration

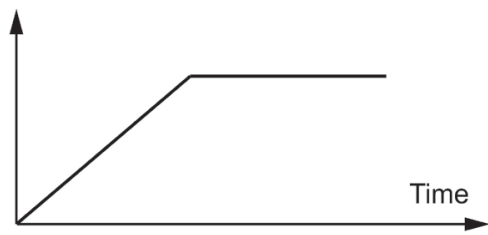

AccSet 10030

Fig. 4. Methods of defining acceleration

- Vel Stel 50, 800;

The instruction will change all programmed velocity values by $50 \%$, and none of the instructed velocities will exceed $800[\mathrm{~mm} / \mathrm{s}]$.

Defining acceleration and deceleration in RAPID can be done by defining the acceleration percentage and the acceleration increment percentage. The method of changing the acceleration values set with the function AccSet is shown in Figure 4 [5].

Figure 4a shows the nominal acceleration values that are maximum to the given robotic test stand design. Percentage changes of the values are possible, for instance by applying the AccSet function with parameters. The first parameter is the limit of the nominal acceleration percentage values. Figure $4 \mathrm{~b}$ shows an example of reducing the acceleration to $30 \%$ of the maximum acceleration. The second parameter is the acceleration increment rate. Figure $4 \mathrm{c}$ shows an example where the acceleration increment is limited to $30 \%$ of the standard value.
The system parameters and the kinematic parameters of $\mathrm{ABB}$ robots running with the IRC controller can be monitored with the RobotStudio software that features the Signal Analyzer application $[3,9]$. This tool facilitates recording a series of defined values at a speed of $40 \mathrm{~Hz}$. The registered parameter values can be monitored online on scaled graphs and saved to TXT or XLS files. Figure 5 shows an example of the application window.

The entire program which handles the stator vane thickness inspection process on the robotic test stand has over 3,000 motion instructions, and the program execution time is approximately 15 minutes. Hence, the method of acceleration and velocity selection is demonstrated with a simplified real-life example (Fig. 2 and 3).

The method was applied by analogy to all stages of motion of the actual test stand. The research work discussed here reduced the power consumption level by $15 \%$ while keeping the test stand cycle time below 15 minutes.

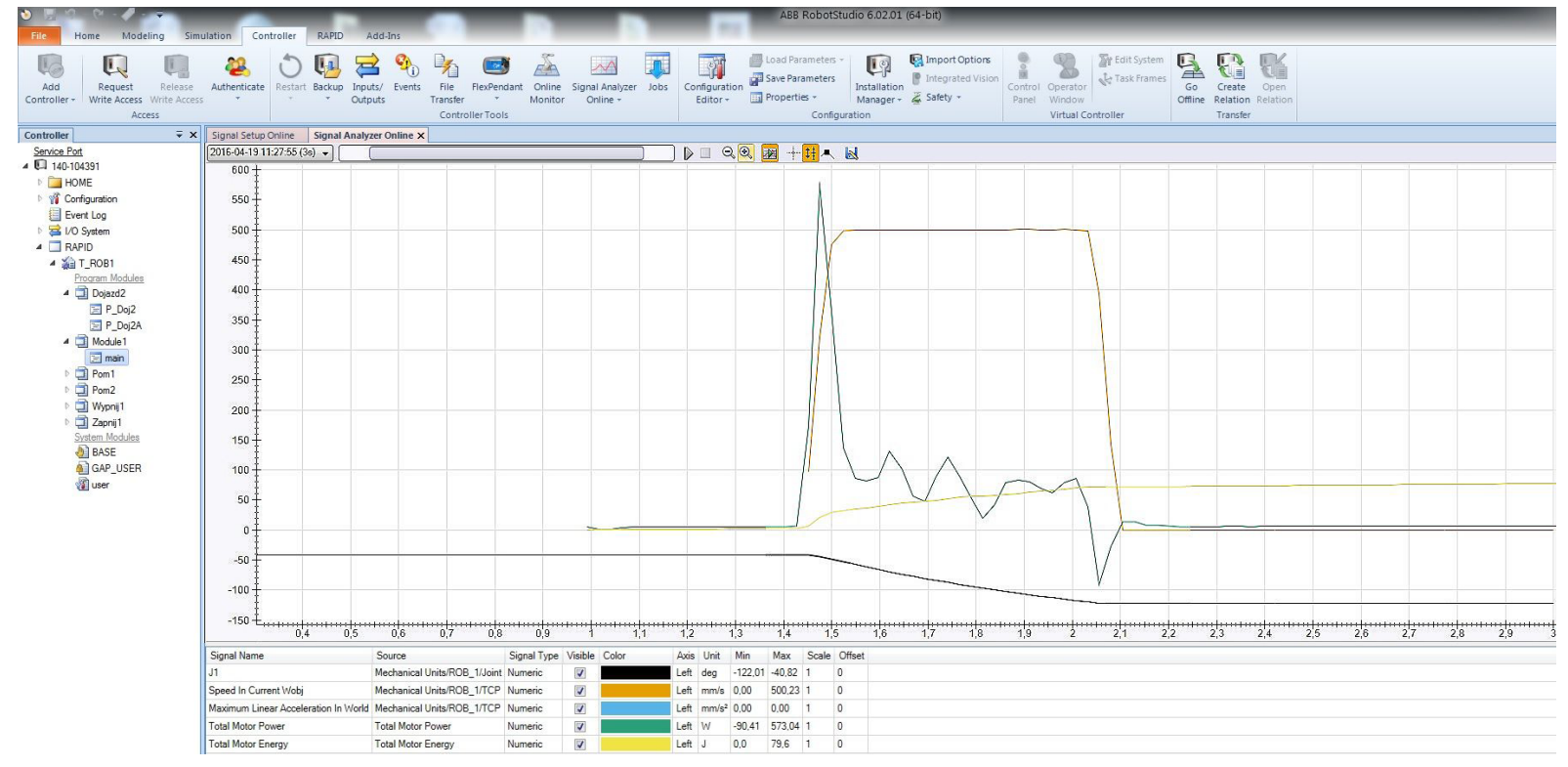

Fig. 5. Example of an application window in RobotStudio Signal Analyzer 

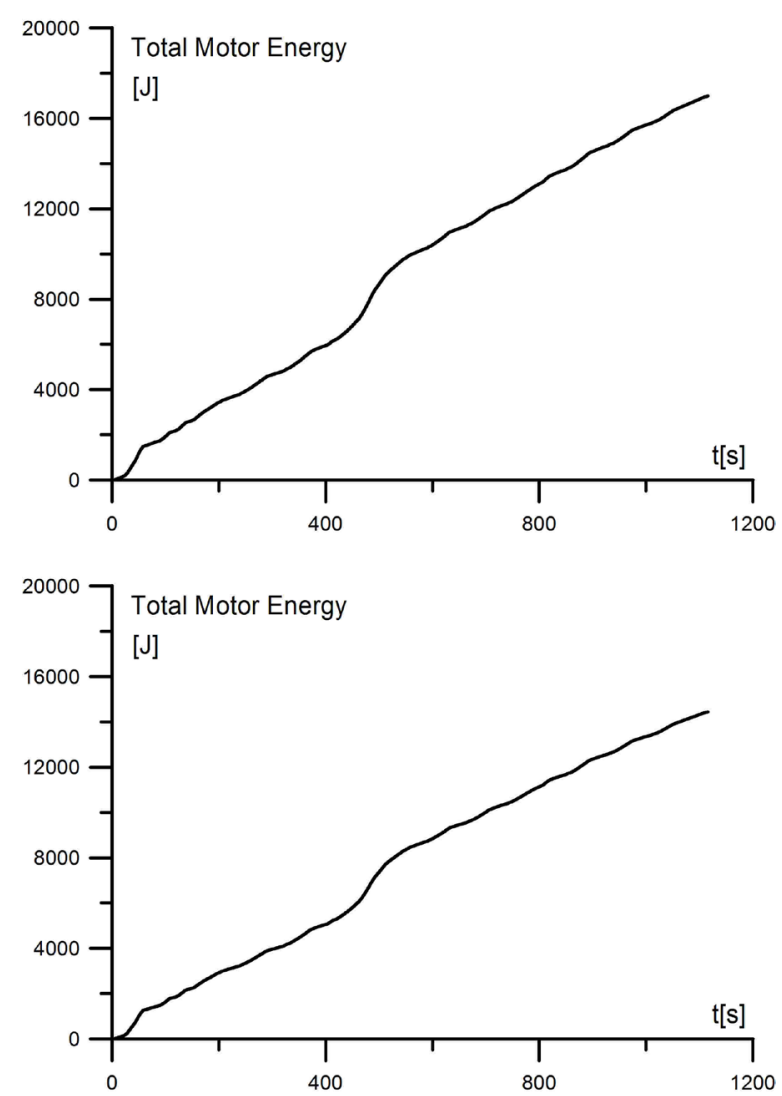

Fig. 6. Power consumption chart

Figure 6a shows the registered chart of the power consumption before the parameter selection, and Figure $6 \mathrm{~b}$ shows the power consumption after the parameter selection.

\section{CONCLUSIONS}

The proposed method for control signal analysis and parameter change helped reduce the power consumption of the actual robotic test stand by $15 \%$ without changing its processing time. The selection of motion parameters of the robotic test stand that reduces the power consumption by tenodd percent is crucial to manufacturing cost efficiency. In the long run, the research demonstrated here provides major financial advantages. The proposed method procedure is applied manually. Further research will be focused on tools suggested for an automated selection of system parameters.

\section{Acknoledgements}

The authors gratefully acknowledge the funding of the Polish National Centre for Research and Development. The project was realized within the frames of the Program Demonstrator Plus UOD-DEM-1-557/001.

\section{REFERENCES}

1. Edmonds S., Lindberg R., Energy optimisation of an industrial robot using iterative dynamic programming, Department of Signals and Systems Division of Automatic Control, Automation and Mechatronics Chalmers University Of Technology Gothenburg, Sweden, 2014.

2. Field G., Stepanenko Y., Iterative dynamic programming: an approach to minimum energy trajectory planning for robotic manipulators. vol. 3 (1996), 2755-2760.

3. Kaczmarek W., Minda Ł., Panasiuk J., Projekt interfejsu operatora dla zrobotyzowanego procesu spawania, Mechanik 7 (2015), 367-376.

4. Kyriakopoulos, Konstantinos J., George N. Saridis., Minimum jerk path generation. In Robotics and Automation, 1988. Proceedings., 1988 IEEE International Conference on, IEEE, 364-369.

5. Nilsson, Klas. Industrial robot programming. Diss. Lund University, 1996.

6. Pan X., Chen Y., Yan L. Research of Multi-robot Cooperation Simulation and Monitoring System Based on Java. In: 2006 6th World Congress on Intelligent Control and Automation, 2006.

7. Wang L. Collaborative robot monitoring and control for enhanced sustainability. The International Journal of Advanced Manufacturing Technology, 81(9-12), 2015, 1433-1445.

8. Wu B., Zhou B.H., Xi L.F. Remote multi-robot monitoring and control system based on MMS and web services. Industrial robot: an international journal 34(3), 2007, 225-239.

9. Zieliński J., Słowikowski M., Puchalski S., Pilat Z. Możliwości realizacji inteligentnego nadzoru instalacji spawalniczych $\mathrm{z}$ wykorzystaniem rozwiązań ICT oraz serwisów WEB 2.0. Pomiary, Automatyka, Robotyka, 16, 2012, 123-127. 